\title{
The impacts of COVID-19 on the logistic ecosystems and benefit for the circular economy
}

UDC 338.121:658.567]:658.78\}:616.98:578.834(4-672EU)

\author{
Riste Temjanovski, ${ }^{1}$
}

${ }^{1}$ University Goce Delcev Stip, Faculty of Economics, riste.temianovski@ugd.edu.mk

\begin{abstract}
The aim of this paper is to identify the specific reviews about many economic uncertainties concerning with Covid 19 pandemic and then how the world economic landscape will evolve. Furthermore, the research is related to the logistic system during the pandemic by means of a circular economy environment. This analysis will show how issues associated with policy-makers grapple with this public health crisis, they also face the need to mobilize recovery efforts to revitalize an economy throughout the circular economy in the logistic ecosystem and hit by the effects of the pandemic.

The global pandemic of COVID-19 caused catastrophic consequences for the world economy. Judging by the trend of this global pandemic, the expectations are not at all optimistic that this problem will be completed in a short time. All companies involved in the movement, storage and flow of goods are directly affected by the COVID-19 pandemic. In order to easily cope with the problems and difficulties with the Corona virus pandemic, the need for optimization of the supply chain and complete digitalization of the logistics sector in all spheres of our society is imposed as an essential need. Or the time has come for a different economic model that will more effectively address the growing problems in the distribution sector of industries or national economies.

The important role of supply chain, which includes logistics, is an inevitable choice while attempting to make a business sustainable, the often ask question in the science and industry practice. Logistics play a vital role in the integration of circular economy principles in the capital-intensive industry as they facilitate the flow of materials between all actors in the value chain. Circular economics is the much-anticipated "desired" concept of creating values through the rational use of resources and the minimization of the adverse environmental impact of manufactured products at all stages of the product life cycle.

Companies that not keep a breast or do not recognize the importance of effective strategy of "friendly" logistics or do not try to change their own business model to a circular economy, as a kind of a global trend as part of the value chain, risk disrupt customer relationships and can seriously endanger the image and reputation of their company. So, the impetus for change in companies in the logistics sector is encouraged and comes as a kind of pressure from external forces (customers and competition), but also from the internal need to reorganize the business model, stimulated by the need for lower costs, healthy environment and long-term sustainable development as a modern trend of general civilization development and modern business strategies.
\end{abstract}

Keywords: Covid-19 pandemic, circular economy, logistics, supply chain management, resources 


\section{Introduction}

The COVID-19 pandemic has triggered a massive spike in uncertainty. Major uncertainties surround almost every aspect: the infectiousness, prevalence, and lethality of the virus; the availability and deployment of antigen and antibody tests; the capacity of healthcare systems to meet an extraordinary challenge; how long it will take to develop and deploy safe, effective vaccines; the ultimate size of the mortality shock; the duration and effectiveness of social distancing, market lockdowns, and other mitigation and containment strategies; the near-term economic impact of the pandemic and policy responses; the speed of recovery as the pandemic recedes; whether 'temporary' government interventions and policies will persist; the extent to which pandemic-induced shifts in consumer spending patterns will persist; and the impact on business survival, new business formation, R\&D, human capital investment, and other factors that affect productivity over the medium and long term.[1]

Furthermore, the COVID-19 pandemic has been catastrophic, with tens of millions of cases and more than a million deaths, and severe economic impacts around the world. According to economic analysis, global economic trends are completely disrupted. The world is facing catastrophic health, economic and social problems. For those reasons. With around USD 10 trillion in economic stimulus being unveiled by governments all around the world, there is an unprecedented opportunity to "move away from unmitigated growth at all costs and the old fossil fuel economy, towards a lasting balance between people, prosperity, and planetary boundaries.[2]

According to Ellen Macarthur foundation review,[3] in the unparalleled response to the Covid19 pandemic, trillions of dollars in economic stimulus have been made available around the world while the calls for a recovery that is in alignment with other global challenges, have never been louder. Many see beyond the pandemic a rare opportunity to build a resilient and lowcarbon economic recovery. Achieving this goal requires governments to take critical actions that not only focus on safeguarding national economies during crises, but that also pave the way toward a wider economic transformation that is more resilient against future global risks.

Undoubtedly, the pandemic crisis has huge implications for the mobility and connectivity of people and goods, the continuity of transport and logistic services, and therefore the entire sector. This will also have cumulative impacts on the economic activity of freight logistics, regions as well as related industries, markets and supply chains. The consequences of such market and sectoral disturbances were reflected in the increase of commodity prices, their unequal distribution, increased global competition for access to certain resources, periodic problems with providing stable access to selected raw materials, efficient use of raw materials. events with the Pandemic of Covid- 19 crisis, which affected almost the entire world.

EU leaders have clearly stated that the COVID-19 economic recovery must go hand in hand with other strategic priorities: an economy more resilient to future shocks, capturing the opportunities of digitisation, finding sources of industrial renewal, and meeting climate targets. EU leaders rightly recognize this as a watershed moment: major investments are in preparation both at the EU level and within the Member States, and they could shape the continent's economic development trajectory for many years. According to some analyzes and projections, the role of the circular economy in the recovery of the European and global economy is more than necessary. EU institutions and economy policy creators examine the potential benefits in the context of the EU's COVID-19 recovery priorities and lay out an agenda for action. They find that a transition to a more circular economy can make significant contributions to EU priorities for resilience, jobs, and environmental protection, while also offering a major opportunity in pure economic terms - both near-term stimulus and longer-term productivity.[4] Business leaders, consumers and governments alike have discovered that continued wealth generation requires a new industrial model that is less dependent on primary energy and 
materials inputs, and ultimately able to regenerate our natural capital.[5] This action might include the enabling of necessary technical innovation, creating new or redesigning existing infrastructure, identifying circular-based business models, circular procurement or setting in motion the right environment for citizens to adopt sustainable lifestyles.[6] Furthermore, the circular economy, as an instrument to decouple economic growth from resource use and environmental impact, opens up the way for a resilient recovery. It not only addresses the negative impacts of the linear economy, but more importantly it represents a systemic shift that builds long-term resilience, generates business and economic opportunities, and provides environmental and societal benefits. [7]

\section{Moving from linear towards circular economy}

We live in a world where demand and competition for finite and sometimes scarce resources will continue to increase, and pressure on resources is causing greater environmental degradation and fragility. Since the industrial revolution, our economies have developed a "take-make-consume and dispose" pattern of growth - a linear model based on the assumption that resources are abundant, available, easy to source and cheap to dispose of.

The notion of circularity in economic production-consumption processes has been launched in the past decade as the latest stage in the evolutionary debate on sustainability. Since the end of the previous century notions such as "people-planet-profit", "cradle-to-cradle", "multivalue creation" and "responsible entrepreneurship", dominated the discourse on sustainability. Alternative technologies, such as the concept of cradle-to-cradle and closing the loop, took hold when economic analysis showed the enormous benefits of circular resource management. As this economic benefit can very well coincide with social and environmental value creation, the concept of a circular economy was embraced as a very attractive and new sustainable economic principal.[8]

Moving towards a more circular economy is essential to deliver the resource efficiency for smart, sustainable and inclusive growth". This rate of pulsation of humanity, where it was paid for unplanned depletion of natural resources has proved unsustainable model. This disproportionate and uncontrolled increase in the demand for resources, as well as the uncontrolled accumulation of waste from used products, brings into question our current predominantly linear economic system.

Modern and highly developed and moral societies often require a degree of synergy between resource efficiency / circular economics and policies related to economics and climate and energy. Synergies with the climate and low-carbon agendas, however, are driven by a combination of environmental considerations, climate change mitigation, regulatory pressures, national greenhouse gas reduction targets and security of supply issues.[9]

Since the industrial revolution, our economies have developed a "take-make-consume and dispose" pattern of growth - a linear model based on the assumption that resources are abundant, available, easy to source and cheap to dispose of. The material flow process of the traditional economy is a "resources - products - waste" one-way linear flow process. The concept of the circular economy is opposed to the traditional economy. Moving towards a more circular economy is essential to deliver the resource efficiency for smart, sustainable and inclusive growth".[10] This rate of pulsation of humanity, where it was paid for unplanned depletion of natural resources has proved unsustainable model. 


\section{From a Linear Economy...}

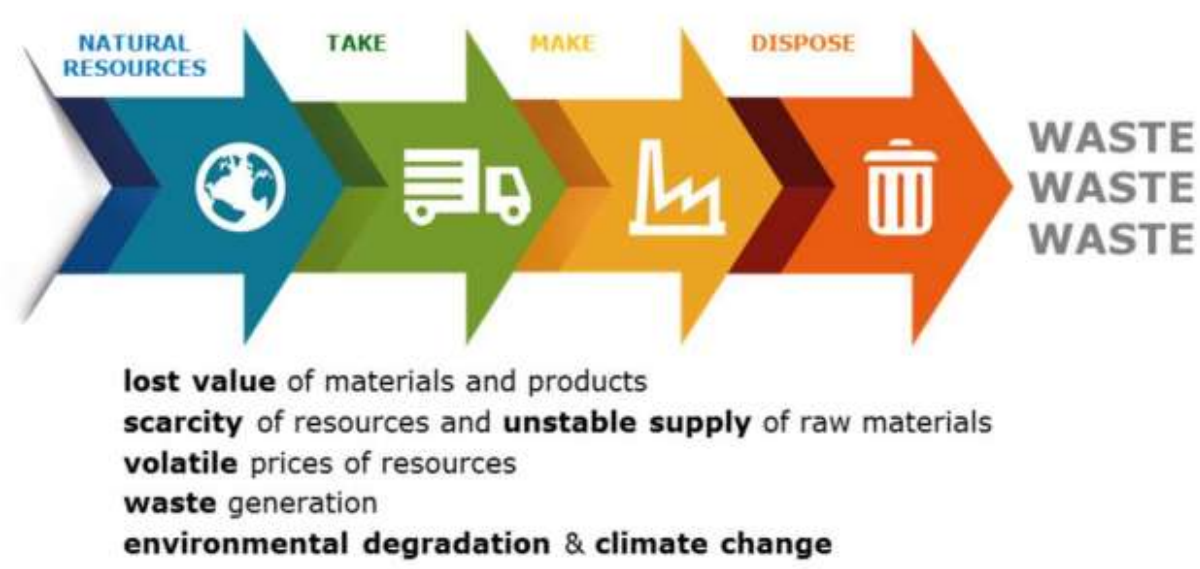

Figure 1 The main direction from a Linear economy

Source: European Commission. Circular economy: closing loop - an EU action plan for the circular economy. 2016. p.3 [11]

The last few decades can be marked as critical and turbulent period of civilization development. The need and use of raw materials has been and continues to be in a ruthless relationship with nature. Increased competition in the global market has also been reflected in increased demand for resources of various natures (energy, aquatic, plant-animal, soil) which has led to many climate changes and threats to human survival. The market deterioration, determined by the weakening of market mechanisms, the spread of the economic crisis, which started in 2008, wildly fluctuating prices of raw materials and commodities, growing concerns about access to critical raw materials and the swift rise of climate change up the policy agenda have all had a significant impact on how resources are adopted and used and what policies have been applied.

The European Commission discussion on critical raw materials reports that, historically, the indispensable role of metals, minerals, rocks and biotic materials has had a low profile. However, more recently, securing reliable, sustainable and undistorted access to crucial nonenergy raw materials has been of growing concern in economies such as those of the EU, USA and Japan.[12]

According to EU's statistical data,[13] each person consumes 16 tonnes of material a year, of which 6 tonnes become waste and half of that is landfilled. The global material use has increased 10 times since 1900 and it is expected to increase by $75 \%$ from 2005 and 2030 . The growth of the global economy and the middle class will put further demands on food, animal feed and other resources will increase by $70 \%$ by 2050 , but already now $60 \%$ of the world's major ecosystems that produce those resources have already been degraded or used unsustainably. If we carry using the resources at the current rate, by 2050 we will need more than two planets to sustain us.

Our current modes of production and consumption remain overwhelmingly based on the linear principle. Resources are extracted, processed, used, and ultimately for the most part discarded as waste. At the end of such a cycle, waste is typically disposed of by incineration (thermal utilisation) or landfill. In both cases materials are withdrawn from circulation or destroyed (even if thermal utilisation does at least produce energy). This disproportionate and uncontrolled increase in the demand for resources, as well as the uncontrolled accumulation of waste from used products, brings into question our current predominantly linear economic system. 
According to expert estimations, Covid-19 triggered the most severe economic recession since the Great Depression in the 1930s, with GDP declines of more than $20 \%$ and a surge in unemployment in many countries. More importantly, the current crisis impacted with Covid 19 pandemic has highlighted the shortcomings of our linear system. This is a system in which resource extraction and waste production - which are inherient to the way we make and produce goods - cause untenable environmental degradation, climate change, biodiversity loss, and pollution.[14]

\section{The circular economy: a new hope for a brighter future}

Contemporary global issues such as unequal distribution and scarcity of resources, soil, air and sea pollution, and volatility in commodity prices are becoming increasingly crucial issues for modern business models. The questions are openly asked how to mitigate these consequences, to solve the accumulated problems and to implement the policy of sustainable development in the long run. Global business recognizes the risk, but how to find long lasting instrument to resolve the problem. One of the possible solutions is hope of implementation the circular economy as driving force in global challenges.

We can find a wide range of concepts, definitions, explanations for the model of the Circular Economy. In its simplest form, the Circular Economy moves away from the traditional classical economic model of "take-makedispose" at the one that is regenerative by design. The goal is to retain as much value as possible from resources, products and parts to create a system that promotes long life, digitization, sharing, services across materials, energy and water. (WBCSD, 2017) [15].

One of the most remarkable insight is to understand the merge and grasp the scale of circular economy opportunities, to understand the shortcomings and possible limits of our current linear economic model. It seems that today's linear economic model reaches a tipping point. The most analysis warned that the current modes of production and consumption remain overwhelmingly based on the linear principle. Resources are extracted, processed, used, and ultimately for the most part discarded as waste. At the end of such a cycle, waste is typically disposed of by incineration (thermal utilisation) or landfill. In both cases materials are withdrawn from circulation or destroyed (even if thermal utilisation does at least produce energy). In 2012, the 28 Member States: [16]

$>$ Consumed 5 billion tonnes of material of which 80 per cent (4 billion tonnes) came from virgin materials and only 20 per cent ( 1 billion tonnes) came from secondary raw materials recovered from the waste stream - giving a recirculation rate of 20 per cent.

$>$ Disposed of 2.5 billion tonnes of waste, 42 per cent ( 1.2 billion tonnes) went to landfill However, such a linear economic model can only function if limitless resources are available to satisfy endless demand. Global demand is growing steadily, while the availability of both non-renewable and renewable raw materials is finite. A strictly linear economy will inevitably encounter limits. 


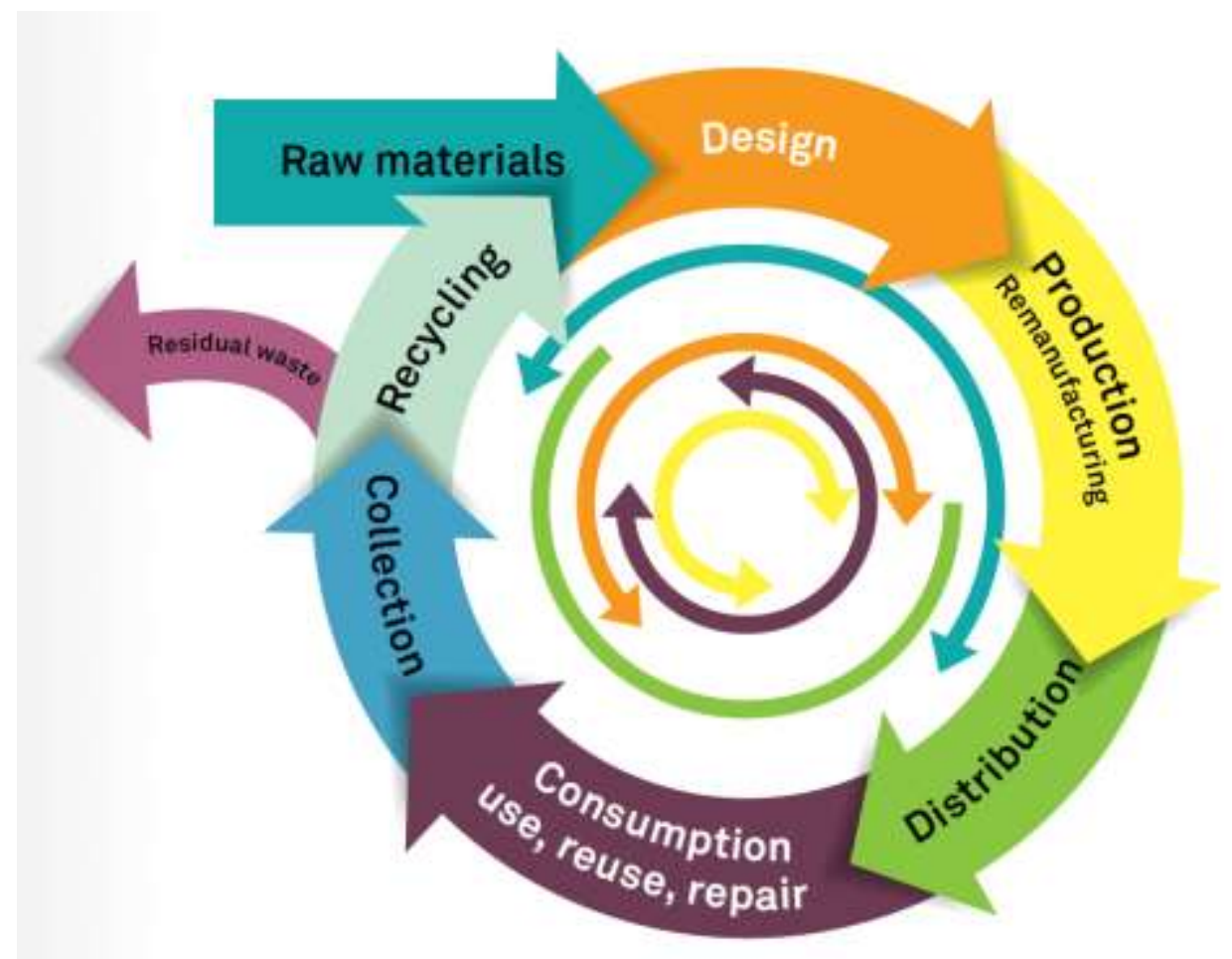

Figure 2 From iner to circular economy [17]

According to Cardoso [18] one of the leading promoters of the idea of the circular economy in the early 1980s. was Walter Stahel, a Swiss architect, who co-founded the Product-Life Institute in Geneva. In a more recent text, in which he revisits and synthesizes his contributions in this field, he defines the circular economy as follows: A circular economy would turn goods that are at the end of their service life into resources for others, closing loops in industrial ecosystems and minimizing waste. It would change economic logic because it replaces production with sufficiency: reuse what you can, recycle what cannot be reused, repair what is broken, remanufacture what cannot be repaired.

In circular economic theory, the primary goal is not to create cycles of material and energy flows (these are largely known), but to transform business processes into sustainable, closedloop resource systems. Thus, according to the new business models, in the circular economy, we no longer talk about value chains, but circular value circle, because these value ranges contain the full spectrum of activities performed by different actors: a product or a service is not only delivered to the user, but its remnants (material and energy) are also transported back into the system. [19] Many companies across the globe have already adopted circular principles to close the loop on energy and material through efforts such as renewable energy investments and recycling. Pioneering innovators have realized the circular economy is not only about resource supply and use efficiency, but indeed even more about evolving their business models to transform the nature of resource demand from the customer's point of view, as in the case of the power tool. [20]

In this world of many challenges, especially those for the survival of mankind, structural change is indispensable. However, to hijack Margaret Thatcher's famous expression, "there is no alternative". Or the way out of the many problems we should look for in the clear emphasis in the words of Kerryn Higgs [21] in her impressive paper "Limits to growth: human economy and planetary boundaries": We need a different kind of economy, one designed to meet needs rather than create them; we need to abandon the consumer path to human advancement and the reduction of our choices to monetary terms. The consumer template for the human future has outworn its usefulness. Stimulating consumption in the interests of growth and chasing economies of scale was, perhaps, suitable for the "empty world". In the "full world" (and getting fuller) we need redistributive justice within and between countries and a plan for the rich world 
to reduce its material demands to allow space for the rest of the world to reach material security.

\section{Covid 19 pandemic and implication on global logistic sector}

The spread of the virus is revealing the vulnerability of the global supply chain for goods. Without transport and logistics, there is no trade, but there is no vaccine also. How to supply the most valuable "human stock" in the world without logistic activities. Many countries are involved in the production and distribution of vaccines, which includes many components ranging from preservatives, vials and syringes to needles, cold boxes and freezers. We must agree with the conclusion that the successful management of supply chain means timely intervention with drugs and saving many lives.

There is significant disruption in the supply chain and demand is fast outpacing supply capacity. Many products continued to be produced in the short term, depending on the companies' stocks, but the problem arose in the manner and time of delivery. This problem is especially pronounced in large urban areas, in developing countries, landlocked countries. Manufacturers of supplies will be (in many cases) located in geographical locations far from where the goods are needed due to the inability to deliver them directly, due to the measures taken by most countries in the world to meet the spread of the Covid pandemic. Worsens with large orders from developed countries absorbing supply capacity and unilateral action and export control from multiple countries.

The COVID-19 pandemic has caused significant dislocation in sub-national governments (SNG) revenues, expenditure burdens and priorities, and the capacity to meet these needs. A global recession whose effects could last well beyond 2020 is expected. The World Bank forecasts a 5.2 percent contraction in global GDP in 2020. With more than 80 percent of global economic output generated in cities, where 55 percent of the world's population lives and 95 percent of COVID-19 cases have been reported, subnational governments are directly impacted by the pandemic and are at the forefront of response measures. In emerging markets, urban centers feel the brunt of both the health and economic crises, putting subnational governments, or SNGs, front and center in the efforts to contain COVID-19. SNGs in emerging markets face significant challenges brought on by the pandemic, for example, significantly less use of public transit, dramatically lower sales tax revenue due to retail and tourism closures, and limited capacity to mount an effective health response. Low levels of preparedness compound these vulnerabilities. [22]

The pandemic spread to the all over the world, leading to lockdowns and border closures that restricted the movement of goods. Additional protocols (such as social distancing at warehouses) introduced to ensure the safety of workers contributed to bottlenecks for freight. According to the analysis of the International Finance Corporation,[23] in the European Union, trucks formed 37-mile-long lines on the A4 highway after Poland closed its border with Germany in mid-March. In India, the lockdown created a shortage of truck drivers, which resulted in over 50,000 containers piling up in the ports of Chennai, Kamajarar, and Kattupalli. According to the same source, disruptions in the procurement of raw materials, production and final products were particularly disturbing as the source of the Covid 19 pandemic originally appeared in China as a leading driving force in world trade and global supply chains. China was the most affected global manufacturing hub in the world and has direct and indirect spread operational difficulties across the globe during the initial stages. The supply chains disrupted for the companies having manufacturing facilities in China and the overall trade i.e., exports of manufacturing goods and imports of agricultural commodities to and from China declined. Cargo was backlogged at China's major container ports, travel restrictions led to a shortage of truck drivers to pick up containers, and ocean carriers canceled (or blanked) sailings. The resulting shortage of components from China impacted manufacturing operations overseas. Major industries around the world, including automotive, electronics, pharmaceuticals, medical equipment and supplies, as well as consumer goods, were affected. 
Since the beginning of 2020, more and more countries across the globe shut down borders and limit domestic travel as a response to the novel coronavirus (COVID-19) outbreak. Thus, cancelling almost all flights to control the spread of the virus has affected the entire airline industry globally. This crisis is being felt primarily in public transport and commercial aviation; and, as city, regional and country borders close, the impact on goods, services and production nodes will become more apparent with shortages of products, made worse by stock-piling. This negative demand shock is affecting all modes of transport. Especially disrupting has been registered in mass transit, maritime transport and air transport.[24]

- Mass transit. Passenger volumes are down substantially, both for traditional bus and urban rail services, as well as for ride-sharing platforms. Countless cities around the world have made changes to public transport services to restrict the spread of COVID-19 and ensure the safe mobility of essential workers in the initial emergency response period. Ridership is down significantly, and continued physical distancing means there will be reduced capacity on individual services until the risk from COVID-19 is eliminated, threatening the financial viability of public transport networks.[25]

- Maritime transport. Maritime transport underpins global supply chain linkages and economic interdependency with shipping and ports estimated to handle over 80 per cent of global merchandise trade by volume and more than 70 per cent by value.[26] As a result, when disruptive factors such as pandemics occur, the sector works as a transmission channel that sends shockwaves across supply chains and regions. Disrupted transport networks and supply chains can significantly undermine world trade and economic activity. A significant percentage of container ships and trucking capacity is lying idle and freight prices are plummeting. Crew movements are constrained. Restrictions introduced in response to the pandemic have caused disruptions affecting ports, shipping and supply chains. Various industries faced challenges along their supply chain such as raw material shortages, lead time issues, ocean blank sailings, port closures, reduced working hours at ports, equipment and labor shortages, as well as truck/transport capacity constraints. These obstacles undermine the smooth movement of trade flows and supply chain operations and can significantly erode the transport services trade liberalization and trade facilitation gains achieved over the years

- Air transport. Since the COVID-19 crisis began, the market for passenger airline services has almost total collapsed; This situation leading also to a dramatic reduction in capacity for air freight capacity provided by passenger jets. But we must keep in mind that air cargo has been a vital partner in delivering much-needed medicines, medical equipment (including spare parts/repair components), and in keeping global supply chains functioning for the most timesensitive materials. This has been done through dedicated cargo freighter operations, utilization of cargo capacity in passenger aircraft, and relief flights to affected areas.

It must also be taken into account that The negative demand-shock on transport demand is visible and, in some cases, devastating. The International Road Union estimates the decline in global road transport activity of up to 20 percent in 2020, depending on how long the situation continues, and the impacts on aviation, public transport and maritime are even higher.

Therefore, the focus of the experts is on optimizing and resilience the supply chain both within and across international borders. As an integral part of value chains, logistics firms facilitate trade and commerce and help businesses get their products to customers. Supply chain disruptions to the sector caused by the pandemic could, therefore, impact competitiveness, economic growth, and job creation.

\section{Circular Economy and its implementation in the Logistics and SCM Sector}

The important role of supply chain, which includes Logistics, is an inevitable choice while attempting to make a business sustainable, the often ask question in the science and industry practice. Logistics play a vital role in the integration of circular economy principles in the 
capital-intensive industry as they facilitate the flow of materials between all actors in the value chain. For upstream activities - activities needed for the manufacture of a specific good - the role of logistics can be found in the transportation of components, spare parts and materials to capital-intensive good manufacturers, which enables them to manufacture the product and perform service activities.[27] Fisher [28] stats that supply chains in many other industries suffer from an excess of some products and a shortage of others owing to an inability to predict demand. One department store chain that regularly had to resort to markdowns to clear unwanted merchandise found in exit interviews that one-quarter of its customers had left its stores empty-handed because the specific items they had wanted to buy were out of stock.

As the economy transitions from linear to circular, logistics will change as well. Barreto, Amaral Pereira [29] consider technological innovation and customer demands for sophisticated technology and services promotes as well as the emergence of new challenges, which is increasingly changing industry. This transformation will dramatically influence how organizations will be managed according to the new incentives, and environmental and context configuration. This revolution is causing profound changes, not only in industry but also in society, in the economic rhythm and outlook, in how work is planned and operationalized, in what way should be oriented the human-machine interactions, among other situations. Hightech manufacturing firms must thus have an adequately large in-house fleet size as well as warehousing and advanced IT management systems to accommodate this unpredictable and large demand in reverse logistics. High-tech manufacturing firms also require value-added services to implement recycle, repair, and remanufacture activities. Therefore, the reverse logistics service requirements of high-tech manufacturing firms require transportation, warehousing management capabilities, advanced IT. [30]

Innovation and high technology, according to the natural course of things, manifest the advantages and conveniences with changes in the concept of working in the logistics and supply chain management sector.

The circular economy principles reformulation can potentially be used in the supply chain particularly into a more circular, closed-loop supply chain. The closed-loop supply chain has two distinct flows - forward flows aiming to minimise services and cost, and reverse flows (also known as reverse logistics) to recover the unwanted, broken or end-of-life products from customers for return to the manufacturers. The complexity of products, services, and processes in the closed-loop supply chain increase as the business models of the circular economy grow. [31]

According to Polet, Aspert and Huitema [32] logistical flows in the circular economy can be subdivided into three major flows: distribution logistics, service logistics and reverse logistics.

- Distribution logistics is about the activities (warehousing, inventory management and transport) needed to get a product from the manufacturer to the end-user.

- Service logistics encompass the numerous activities as well as: maintenance, repair, refurbishment, and refurbishment that apply to product components necessary to ensure the proper operation of a capital-intensive product. Service logistics are expected to significantly increase and accelerate the processes of transition to a circular economy. This increase in more complex logistics will certainly result in additional costs. But the environmental impact of these extra logistics and extra financial costs needs to be compensated for in other parts of the business model (e.g. by lower virgin material demand) to make it a feasible choice.

Reverse logistics take place at the end-of-use phase, which, in this research, occur only once, i.e. the moment at which the product as a whole is discarded. Increasing attention has been given to reverse logistics $(R L)$ and closed loop supply chain (CLSC) markets and business models over the last decade. This is due in part to the recognition of increasing value of the products and technology created in the field at the end of general direct supply chains and the impact of green laws, particularly in Europe. The problem and concerns of the ultimate disposal of junk, trash, and waste has always been an issue as a function of urbanization, and the increasing population density of metropolitan areas.[33] Reverse logistics as such concern complete product returns, 
product transfers to third parties and integration of discarded products in production planning. One obvious change is the growing importance of reverse logistics (as opposed to forward logistics of bringing a product to the customer), which concerns the activities related to products, components and materials returning into the value chain. Brito and Dekker [34] present the Reverse Logistics model in a similar way emphasizing similar attributes. Namely, reverse logistics concerns activities associated with the handling and management of equipment, products, components, materials or even entire technical systems to be recovered (for succinctness we will often use the term products alone). Recovery can simply be just reselling a product. It can be accompanied by a series of processes as collection, inspection, separation, and so on, leading to e.g. remanufacturing or recycling. Material recapture and product or equipment (partial) reuse is a very old practice. In the past, the primary motivation was scarcity of resources. In this view and the insight of reverse logistics are not a new phenomenon, as organisations have recognised the competitive advantage it can give for a long time. Reverse logistics thus comprises activities involved in the collection, disposal of products and materials, their recycling, remanufacturing, refurbishing, reuse and reselling, but also resource reduction.[35] Yet before any of such activities incur, an important decision in reverse logistics is that of gatekeeping, that determines what is to be collected in the first place - and the very avoidance of returns. The latter point is again a divisive one, as reverse logistics is either defined narrowly as to focus on any "backwards" material flow in the supply chain, or more widely to denote also questions of resource reduction, dematerialization, design for disassembly and ecological product development. But as the very term "reverse" logistics may not easily lend itself to denote also "forward", regular material flows, the concept of "closed loop supply chains" (CLSC), and closed loop supply chain management was coined. Indeed, depending on whether reverse flows are used in the original or in secondary supply chains and/or involve new auxiliary channel members, one can even distinguish between closed, and open-loop ones.[36]

According to Stolka-Seroka and Kubicka-Ociepa [37] circular economy is the concept of creating values through the rational use of resources and the minimization of the adverse environmental impact of manufactured products at all stages of the product life cycle, which enable the reuse of materials used. In its basic assumptions, the circular economy concept uses both old and new concepts that promote the mitigation of the adverse environmental impact of products manufactured by companies, and include the following concepts:

$>$ from cradle to cradle $(\mathrm{C} 2 \mathrm{C})$

$>3 \mathrm{R}$ (reduce, reuse, and recycle); 4R (reduce, reuse, recycle and, repair) or 9R [38] (refuse, reduce, reuse, repair, refurbish, remanufacture, repurpose, recycle, recover energy)

$>$ cleaner manufacturing

$>$ industrial ecology

$>$ sustainable supply chain management

$>$ green supply chain.

All of the above-mentioned concepts fit into the realization of the idea of sustainable development. It's worth adding here another concept, namely that of green logistics, which is the prerequisite and key element of the development of circular economy. Green logistics combines the aforementioned concepts and promotes the sustainable development idea .

In today's societal practices, important steps have been taken to introduce processes of reuse, repair and recycling, adding significant feedback loops to the linear production-consumption model. These loops are often approached as separate optimization steps. The concept of circularity, however, goes substantially further. First, it focuses on designing products in such a way that they can be easily repaired, disassembled for renewed use of components, or enable an easy recuperation of raw materials.[39]

One of the key attractions of green infrastructure is its multifunctionality, i.e. its ability to perform several functions and provide several benefits in the same spatial area. [40] These functions 
can be environmental, such as conserving biodiversity or adapting to climate change, social, such as providing water drainage or green space, and economic, such as supplying jobs and raising property prices.

According to Saroha [41] green logistics is a form of logistics which is calculated to be environmentally and often socially friendly in addition to economically functional. It describes all attempts to measure and minimize the ecological impact of logistics activities. This includes all activities of the forward and reverse flows of products, information and services between the point of origin and the point of consumption. It is the aim to create a sustainable company value using a balance of economic and environmental efficiency. [Figure 3].

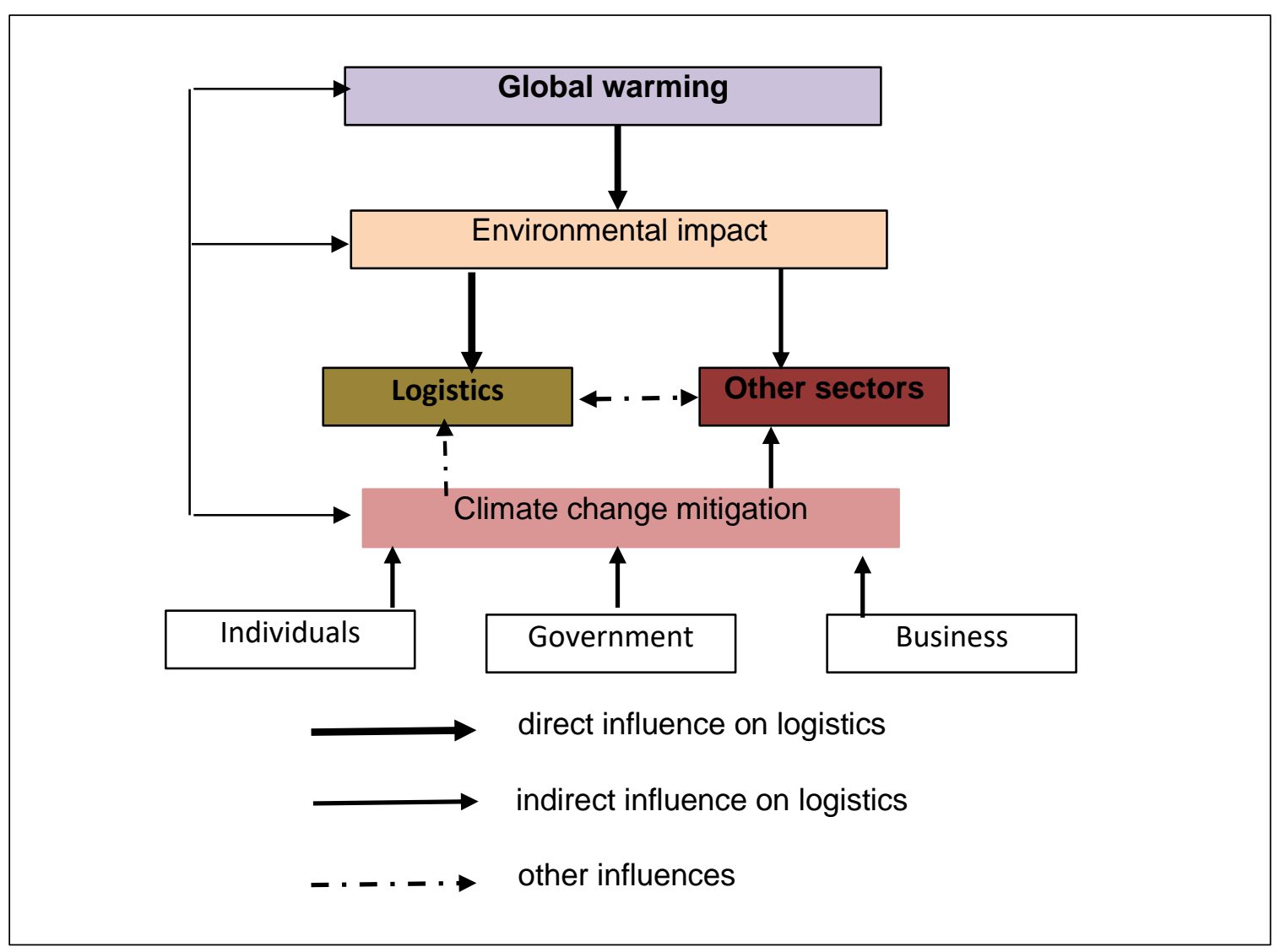

Figure 3 Direct and Indirect Pressures on Logistics to Adapt to Climate Change

Source: McKinnon A., Kreie A. (2010): Adaptive logistics: preparing logistical systems for climate change. Paper to be presented at the Logistics Research Network Conference in Harrogate, 8-10 Sept 2010 p.3. [42]

In the concept of circular economy also mentions and notion the green supply chain management. For the green supply chain management, there is not an integral definition in theory circle. The definition of green supply chain management varies as researchers stand at different angles. After a comprehensive analysis, the following idea could be adopted: under the guidance of the sustainable development theory and the basic principle of supply chain management, the logistics, information, capital and knowledge flow are planned, organized, led, coordinated and controlled among the participating subjects for the whole green supply chain, which aims to optimize the resources allocation, increase benefits and achieve the goal of environmental compatibility through such means as the optimization and improvement of related activities speed, certainty, the friendly degree with environment. Green supply chain management requires thoroughly changing the idea of "treatment after pollution" and 
emphasizes the concept of "reduction of pollution at source, prevention first, treatment second, namely, at the design of product and purchase stages, full consideration shall be made about its impact on environment, thus reducing enterprise treatment costs and improving enterprise environmental performance and economic performance.[43]

\section{Conclusion}

Over the last years, the question of circular economy has become a topic of priority for every country of the world. Our insight concern that only through collaborative action can progress be achieved in this important and subtill question. This action might include the enabling of necessary technical innovation, creating new or redesigning existing infrastructure, identifying circular-based business models, circular procurement or setting in motion the right environment for citizens to adopt sustainable lifestyles.

Circular Economy is the most important and contemporary strategy in environmental conservation. The focuses on this new concept is waste and waste management after using, processing and consumption of goods. This concept has significant implications for the phases of use, production process and packaging. Simply said, the circular economy is an economic model that focuses on waste and waste management, after reuse, by reusing resources, repairing and recycling instead of producing entirely new ones to reduce the use of raw materials and recycle as much as possible. As well as increasing the efficiency of the product or packaging, there is no negative impact both social and environmental. Tackling environment protect, insufficient natural resources and climate change calls for course-correction and a systemic-thinking approach. To achieve such a big shift, climate mitigation strategies must harness the transformative power of the circular economy.

Circular economics as an alternative model focuses on separating growth from underutilization of resources - provides the key to managing this challenge at both macro and micro levels, enabling economic development within the limits of natural resources, and enabling companies to innovate to enable customers and users to do "more with less". The circular economic model is basically a complex system that with its mechanisms replaces the classic, one-way concept of the life cycle, offering a new systemic order to the so-called redesign of material flows, enabling the use of renewable energy sources.

Countries around the world are increasingly turning their attention to the urgent reduction of environmentally harmful subsidies (taking into account OECD recommendations and definitions), with particular emphasis on fossil fuel subsidies and the use of clean water in agriculture, energy and industry. In terms of stimulating certain fiscal benefits (payment schemes, duties and taxes), they should be significantly accompanied by price reductions. Special incentives and benefits should be given to countries that are financially unable to bear all this burden and Member States should be encouraged to shift the tax burden from workplace to resource use in order to promote resource efficiency.

Further waste reduction, fostering high quality waste management and increasing the recycling process have significant potential for job creation and higher and more stable growth. All these benefits can be achieved through better implementation and promotion of the best available techniques and practices and modern approaches to exploring friendly materials. 


\section{References}

1. Baker S., [et all]. COVID-induced economic uncertainty and its consequences. 13 April 2020 https://voxeu.org/article/covid-induced-economic-uncertainty-and-its-consequences 17.04.2021]

2. The Club of Rome, Open letter to global leaders - a healthy planet for healthy people (26th March 2020)

https://www.clubofrome.org/impact-hubs/climate-emergency/open-letter-to-global-leaders-a-healthyplanet-for-healthy-people/ [accessed 17.04.2021]

3. Ellen Macarthur Foundation (2020): Circular economy and the Covid-19 recovery: How policymakers can pave the way to a low-carbon and prosperous future. www.ellenmacarthurfoundation.org [accessed: 17.04.2021]

4. Material Economics Sverige AB. The Circular Economyand covid-19 Recovery:How pursuing a circular future for Europe fits with recovery from the economic crisis. https://materialeconomics.com/latest-updates/circular-recovery [accessed 17.04.2021]

5. World Economic forum (2014): Towards the Circular Economy: Accelerating the scale-up across global supply chains. Prepared in collaboration with the Ellen MacArthur Foundation and McKinsey \& Company. WEF, January 2014. p.10

6. Dhawan P., Beckmann J. (2018): Circular Economy Guidebook for Cities. CSCP, 2018.p.3.

7. Ellen Macarthur Foundation (2020): Circular economy and the Covid-19 recovery: How policymakers can pave the way to a low-carbon and prosperous future. www.ellenmacarthurfoundation.org [accessed: 17.04.2021]

8. Buren V.N. et all. (2016). Towards a circular economy: the role of Dutch logistics industries and governments. Sustainability 2016, 8, 647; p.2. doi:10.3390/su8070647

9. European Environment Agency (2020): Resource efficiency and the circular economy in Europe 2019 - even more from less: An overview of the policies, approaches and targetsof 32 European countries. Luxembourg: Publications Office of the European Union, 2020. No 26/20191994. p.11.

10. Wilts H., Gries N.V., Walkowiak B.B. (2016): From Waste Management to Resource EfficiencyThe Need for Policy Mixes. Sustainability 2016, 8, 622; doi:10.3390/su8070622. p.1. https://epub.wupperinst.org/frontdoor/deliver/index/docld/6403/file/6403_Wilts.pdf [accessed 25.02.2021]

11.https://ec.europa.eu/environment/legal/law/6/pdf/01_aile_waste_law_circular_economy_s peakers_notes.pdf

12. European Parliament (2017): Towards a circular economy - waste management in the EU. EPRS: Scientific foresight unit (STOA) PE 581.913. p.28.

13. European Commission. Circular economy: closing loop - an EU action plan for the circular economy. 2016. p.3.

https://ec.europa.eu/environment/legal/law/6/pdf/01_aile_waste_law_circular_economy_speakers_not es.pdf

14. Ellen Macarthur Foundation (2020): How policymakers can achieve a resilient recovery with the circular economy.p.2-3. www.ellenmacarthurfoundation.org [accessed: 17.04.2021]

15. WBCSD (2017). 8 Business cases for the circular economy. Geneve: WBCSD, 2017. p.2. https://www.wbcsd.org/Programs/Circular-Economy/Factor-10/News/8-Business-Cases-to-the-

Circular-Economy [accessed: 19.02.2021]

${ }^{16}$. European Parliament (2017): Towards a circular economy - waste management in the EU. EPRS: Scientific foresight unit (STOA) PE 581.913. p.16

17. https://aecom.com/without-limits/article/keeping-tabs-waste/circular-economy/ [accessed 24.02.2021]

18. Cardoso, J. L. (2018). "The circular economy: historical grounds". In Changing Societies: Legacies and Challenges. Vol. iii. The Diverse Worlds of Sustainability, eds. A. Delicado, N. Domingos and L. de Sousa. Lisbon: Imprensa de Ciências Sociais, 117.

https://doi.org/10.31447/ics9789726715054.04

19. ogarassy C., Finger D.(2020). Theoretical and Practical Approaches of Circular Economy for Business Models and Technological Solutions. Resources 2020, p.1-2.; doi:10.3390/resources9060076 20. Accenture strategy (2014). Circular Advantage Innovative Business Models and Technologies to Create Value without Limits to Growth.2014. p.4.

https://www.accenture.com/t20150523T053139 w /us-en/ acnmedia/Accenture/ConversionAssets/DotCom/Documents/Global/PDF/Strategy 6/Accenture-Circular-Advantage-InnovativeBusiness-Models-Technologies-Value-Growth.pdf 
21. Higgs K. (2017): Limits to growth: human economy and planetary boundaries. The Journal of Population and Sustainability. Vol. 2, No. 1, (Autumn 2017), p.31

22. World bank group: Covid-19's impact on Sub-National Governments. p.1-2.

https://www.ifc.org/wps/wcm/connect/cb8caf2a-0dde-4620-9e3d-7df8c4717fa6/IFC-Covid19-

Municipalities-final102120-web.pdf?MOD=AJPERES\&CVID=nlc.KIU [accessed 16.04.2021]

23. International Finance Corporation:The impact of Covid-19 on logistics. p.2-3.

https://www.ifc.org/wps/wcm/connect/2d6ec419-41df-46c9-8b7b-96384cd36ab3/IFC-Covid19-

Logistics-final_web.pdf?MOD=AJPERES\&CVID=naqOED5 [accessed 16.04.2021]

24. Infrastructure: WBG Response to COVID-19 The Transport Sector: A Mobility Crisis.p 1.

25. C40 Cities Climate Leadership: Group Public transport after COVID-19: re-building safe and connected cities. https://www.c40knowledgehub.org/s/article/Public-transport-after-COVID-19-rebuilding-safe-and-connected-cities?language $=$ en_US [accessed 16.04.2021]

26. UNCTAD (2020): COVID-19 and maritime transport: Impact and responses. UNCTAD /DTL /TLB /INF/ 2020/1. p.9.

https://unctad.org/system/files/official-document/dttltbinf2020d1_en.pdf [accessed 16.04.2021]

27. Polet M., Aspert V.S, Huitema N.: Logistics in the transition to a circular economy: white paper. Amsterdam: Copper, 2020. p.3.

28. Fisher, M. (1997). What is the right supply chain for your product? Harvard Business Review, MarchApril.p.1.

29. L. Barreto, A. Amaral and T. Pereira (2017), "Industry 4.0 implications in logistics: an overview," Procedia Manufacturing, 2017. 13, p. 1245.

30. Cheng H.Y., Lee F. (2010). Outsourcing reverse logistics of high-tech manufacturing firms by using a systematic decision-making approach: TFT-LCD sector in Taiwan. Industrial Marketing Management 39 (2010) 1111-1119

31. Ripanti, E \& Tjahjono, B 2019, 'Unveiling the Potentials of Circular Economy Values in Logistics and Supply Chain Management', The International Journal of Logistics Management, p.22. https://dx.doi.org/10.1108/IJLM-04-2018-0109

32. Polet M., Aspert V.S, Huitema N.: Logistics in the transition to a circular economy: white paper. Amsterdam: Copper, 2020. p.7.

33. Blumberg F.D. (2005): Introduction to Management of Reverse logistics and Closed Loop Supply Chain Processes. Boca Raton London New York Washington, D.C.2005.

34. Brito P.M., Dekker R. (2002): Reverse Logistics - a framework. 2002. p.1. [accessed 25.02.2021

35. Rogers, D.S. \& Tibben-Lembke, R. (1998). Going Backwards: Reverse Logistics Trends and Practices. University of Nevada, Reno Center for Logistics Management. pp.64-65

36. Kovács G.: Circular economy vs.closed loop supply chains: what is under the Sun? in Constructing a green circular society. Helsinki: Faculty of social sciences, University of Helsinki, 2017. p. 8.

37. Stolka-Seroka O., Kubicka-Ociepa A.(2018): Green logistics and circular economy. Transportation Research Procedia 39 (2019) p.472.

38. Cramer, J. (2014): Milieu: Elementaire Deeltjes 16. Amsterdam: Amsterdam University Press. 2014. 39. Heijden van der R., Coenen J., Riel V.A.: Transitioning from a linear economy towards a circular economy: the case of the apparel industry. in Constructing a green circular society. Helsinki: Faculty of social sciences, University of Helsinki, 2017. p.16.

40. Temjanovski, Riste and Jovanov, Tamara (2020) Transforming freight mobility in the cities and promoting of green logistics. Macedonian International Journal of Marketing, 6 (11). pp. 113-121. ISSN $1857-9787$.

41. Saroha R.: Green Logistics \& its Significance in Modern Day Systems. International Review of Applied Engineering Research. Volume 4, Number 1 (2014), pp. 89-92.

42. https://pdfs. semanticscholar.org/26ab/4590e6c4175d5ef9be974c555ab485bcd680.pdf

43. Ying J., Li-jun Z.(2012): Study on Green Supply Chain Management Based on Circular Economy. 2012 International Conference on Solid State Devices and Materials Science. p.1683. 